\title{
PERSEPSI STAKEHOLDER TERHADAP PELAKSANAAN CORPORATE SOCIAL RESPONSIBILITY: KASUS PADA BANK SYARIAH DI DIY
}

\author{
MB Hendrie Anto \\ Fakultas Ekonomi Universitas Islam Indonesia \\ E-mail:hendrie@fe.uii.ac.id \\ Dwi Retno Astuti \\ Alumni Magister Manajemen Universitas Islam Idonesia
}

\begin{abstract}
Corporate Social Responsibility (CSR) is now getting more attention not only from the stockholder but also stakeholder. CSR is considered as a natural consequence of the existence of company in their society in order to maintain their profit in the long term. So, the benefit of CSR would be back to the company itself. In the perspective of Islamic bank, CSR is embedded in the ground of Islamic teachings which look at business as an entity to create maslahah in the society. Profit is necessary, but not sufficient to justify Islamic business. This paper is aim to indentify the perception among stakeholders on CSR practiced by Islamic banks in Daerah Istimewa Yogyakarta. Kruskal Wallis Test, Mann Whitney U-Test, and content analysis are utilized to analyze the data from 116 respondents which is selected with purposive method. In general, the result shows that there is no difference perception among stakeholders on the benefit of CSR practiced by Islamic banks in terms of imej building and competitiveness enhancement. In addition, Islamic banks are supposed to be more socially responsible than the conventional one.
\end{abstract}

Keywords:CSR, perception, stakeholder, maslahah

\section{PENDAHULUAN}

Corporate Social Responsibility (CSR) merupakan wacana penting dalam dunia bisnis sejak tahun 1970an. Dalam historisnya, praktik CSR sendiri berawal dari tahap yang paling sederhana, yakni sifat kedermawanan para pemilik perusahaan. Pada saat ini CSR merupakan kegiatan penting bagi perusahaan-perusahaan modern, terutma dipelopori oleh MNCs ( multinational corporations) (Idris, A.R., 2005). Terdapat berbagai definisi CSR, namun pada intinya menekankan bahwa tanggung jawab perusahaan bukan lagi sekedar kegiatan ekonomi (menciptakan profit demi kelangsungan usaha), melainkan juga tanggung jawab sosial dan lingkungan ${ }^{1}$. Dalam dunia perbankan, CSR juga telah menjadi tren

\footnotetext{
${ }^{1}$ Beberapa definisi CSR antara lain: (a) "CSR is the commitment of busines to contribute to sustainable economic development working with employees and their representatives, the local community and society at large to improve quality of life, in ways that are both good for business and good for development"(World Bank, dalam Djun, 2006); (b) "CRS is a concept whereby companies integrate social and environmental concerns in their business operations and in their interaction with their stakeholders on a voluntary basis" (Uni Eropa, dalam Djun, 2006); (c) CSR adalah komitmen bisnis untuk berkontribusi dalam pembangunan ekonomi berkelanjutan, bekerja dengan para karyawan perusahaan, keluarga karyawan, dan masyarakat setempat (lokal) dalam rangka meningkatkan kualitas kehidupan (The Word Business Council for Sustainable Development, dalam Idris, A.R., 2005).
} 
baru yang menarik. Dalam skala internasional, kegiatan CSR Barclays Bank dapat menjadi contoh yang baik (www. barclays.com). Meskipun demikian, masih terdapat pro dan kontra tentang relevansi CSR dengan bisnis pada perusahaan (Keraf, A.S. dan Imam, R.H., 1995).

Argumen yang mendukung pentingnya CSR bagi perusahaan antara lain: (a) CSR sejalan dengan kebutuhan dan harapan masyarakat yang terus berubah; (b). Perusahaan sebagai bagian dari masyarakat memiliki kewajiban moral terhadap lingkungannya; (c) Terbatasnya sumber-sumber daya mendorong perusahaan untuk bekerjasama dengan masyarakat untuk memeliharanya; (d) Semakin baik lingkungan sosial maka akan semakin baik pula lingkungan bisnis itu; (e) Perimbangan tanggung jawab dan kekuasaan perusahaan; (f) CSR merupakan suatu nilai lebih yang sangat positif bagi perkembangan dan kelangsungan hidup perusahaan dalam jangka panjang.

Sementara itu argumentasi yang menentang CSR antara lain: (a).Tujuan bisnis adalah mengejar keuntungan sebesarbesarnya; (b).CSR dapat mengganggu fokus manajemen perusahaan; (c) CSR dianggap memberatkan masyarakat, karena biayabiaya dibebankan pada produk yang harus dibayar konsumen; (d) Bisnis mempunyai kekuasaan yang sudah memadai, sehingga tidak memerlukan dukungan masyarakat; (e) Kurangnya tenaga terampil yang dimiliki perusahaan; (f) pada dasarnya perusahaan tidak mampu membuat pilihan moral, sehingga sulit membuat keputusan sosial.

\section{CSR dalam Perspektif Islam dan Perbankan Syariah \\ CSR dalam perspektif Islam} merupakan konsekuensi inhern dari ajaran Islam itu sendiri. Tujuan dari syariat Islam (maqashid al syariah) adalah maslahah sehingga bisnis adalah upaya untuk menciptakan maslahah, bukan sekedar mencari keuntungan ${ }^{2}$. Menurut Naqvy (1996), kegiatan ekonomi dan bisnis dalam Islam dilandasi oleh aksioma Tauhid, Keseimbangan, Kebebasan, dan Pertanggungjawaban. Aksioma-aksioma ini harus diimplementasikan dalam seluruh aspek kegiatan ekonomi dan bisnis. Aksioma keseimbangan dan pertanggungjawaban, misalnya, akan membawa implikasi pada keseimbangan dan pertanggungjawaban antara jiwa dan raga, antara person dan keluarga, antara individu dan sosial, antara suatu masyarakat dengan masyarakat lainnya (Beekun, R.I., 1997).

Aktifitas CSR pada dasarnya juga melekat secara inhern pada bank syariah sebagai konsekuensi kebersandaran bank syariah pada ajaran Islam. Berbeda dengan bank konvensional, bank syariah tidak dapat memisahkan secara dikotomis antara orientasi bisnisnya dengan orientasi sosialnya. Orientasi bisnis seharusnya juga membawa orientasi sosial, atau setidaknya tidak kontradiksi dengan orientasi sosial. Hal ini membawa konsekuensi pada kuatnya karakter sosial dari perbankan syariah, relatif jika dibandingkan dengan bank konvensional.

Sebenarnya, dalam pandangan Islam kewajiban melaksanakan CSR bukan hanya menyangkut pemenuhan kewajiban secara hukum dan moral, tetapi juga strategi agar perusahaan dan masyarakat tetap survive dalam jangka panjang. Jika CSR tidak dilaksanakan maka akan terdapat lebih banya biaya yang harus ditanggung perusahaan. Sebaliknya jika perusahaan melaksanakan CSR dengan baik dan aktif bekerja keras mengimbangi hak-hak dari semua stakeholders berdasarkan kewajaran, martabat dan keadilan, dan memastikan

\footnotetext{
${ }^{2}$ Meskipun mencari keuntungan adalah halal, tetapi mencari' karunia Allah' adalah lebih bernilai. Lihat QS, Al Jumu'ah: 9-11.
} 
distribusi kekayaan yang adil, akan benarbenar bermanfaat bagi perusahaan dalam jangka panjang. Seperti meningkatkan kepuasan, menciptakan lingkungan kerja yang aktif dan sehat, mengurangi stres karyawan, meningkatkan moral, meningkatkan produktivitas dan juga meningkatkan distribusi kekayaan di dalam masyarakat (Parvez Zahid dan Ahmed Pervaiz, 2004). CSR juga dapat digunakan sebagai alat stratejik untuk membentuk reputasi dan imej publik terhadap bank syariah sehingga menguntungkan dalam jangka panjang (Dusuki, A.W, 2005).

Tetapi, kenyataannya masih banyak bank syariah yang semata-mata lebih mengutamakan pencapaian keuntungan maksimal, sebagaimana bank -bank konvensional selama ini. Seharusnya mereka menyertakan komponen tanggung jawab sosial dalam kegiatan operasionalnya sebagai tujuan akhir dalam melayani masyarakat secara utuh (Ahmad K., 2000). Dalam studi terhadap 47 bank syariah yang tersebar di 14 negara, perbankan syariah juga ditengarai belum bersikap terbuka dalam melaporkan aktifitas CSRnya, terutama jika dilihat dari laporan keuangan yang dipublikasikan (Farook Syad and Lanis Roman, www.afaanz.org). Program CSR kebanyakan dilakukan dalam bentuk Community Development yang cenderung bersifat karitatif, responsif, berorientasi jangka pendek, dan kurang melibatkan masyarakat. (Sunartiningsih 2004; Ardiyan Rino, 2004). Program CSR seringkali hanya sebagai program peredam gejolak, yang nampak ketika terjadi kasus keributan di dalam masyarakat (Nika, 2005).

Salah satu penyebab lemahnya pelaksanaan CSR kemungkinan adalah karena masih adanya anggapan bahwa CSR adalah sentra biaya (cost center) sehingga akan mengurangi laba perusahaan. Kompetisi perbankan yang ketat dan orientasi maksimasi keuntungan juga seringkali menyebabkan kecenderungan bank syariah untuk lebih melayani kelompok kuat dan profitable. Karenanya, fungsi sosial bank syariah dalam memfasilitasi keterkaitan antara voluntary sector dengan pemberdayaan ekonomi marjinal belum optimal (www.biro kredit indonesia.com, 2006).

Penelitian ini tidak bertujuan untuk mengetahui sejauhmana pelaksanan CSR oleh perbankan syariah, tetapi mengetahui persepsi stakeholder terhadap pelaksanaan CSR. Dengan mengetahui persepsi stakeholder setidaknya diperoleh dua manfaat, yaitu: (a) mengetahui harapan berbagai kelompok stakeholder sehingga kemudian dapat teridentifikasi bentuk CSR yang tepat; dan (b) mengevaluasi pelaksanaan CSR yang selama ini telah dilakukan. Secara lebih rinci penelitian ini berusaha untuk menjawab ada tidaknya perbedaan persepsi antar stakeholder tentang pelaksaaan CSR terkait dengan: Apakah membutuhkan biaya yang besar dan tidak memberikan dampak positif bagi bank syariah; Apakah tidak memberikan keunggulan yang kompetitif bagi bank syariah ; Apakah berlawanan dengan profit maximisation bagi bank syariah; Apakah akan merubah reputasi dan imej publik terhadap bank syariah ; Apakah bank syariah seharusnya menunjukkan level yang lebih tinggi dibandingkan bank konvensional; serta apakah bentuknya sebatas program peredam gejolak (Corporate Social Activity) atau benar-benar Corporate Social Responsibility.

\section{METODE PENELITIAN}

Obyek penelitian adalah stakeholder bank syariah di Yogyakarta, yaitu stakeholder primer dan stakeholder sekunder menurut kriteria 5 bank terkemuka di Australia (Cuganesan Suresh dan Khan Haider, 2006) yang terdiri atas karyawan (kepala cabang dan karyawan), nasabah, regulator (DPBS Bank Indonesia), serta 
masyarakat. Di Daerah Istimewa Yogyakarta terdapat beberapa bank syariah, yaitu: BMI, BSM, BRI Syariah, BNI Syariah, dan BTN Syariah. Kuesioner disebarkan kepada 138 responden yang diambil dengan purposive method, namun yang dapat diolah hanyalah 116 dengan distribusi sebagaimana terlihat pada Tabel 1. Data dikumpulkan melalui kuesioner yang dilengkapi dengan wawancara (jika diperlukan). Skala kuisioner disusun dengan menggunakan metode semantic differentials yang memberikan ruangan penilaian yang lebih luas bagi jawaban responden sehingga informasi menjadi lebih akurat (Singarimbun Masri dan Effendi Sofian, 1989). Data yang diperoleh dianalisis secara kualitatif dan kuantitatif. Analisis kualitatif dilakukan untuk mendapatkan gambaran terhadap pelaksanaan CSR dari sudut pandang stakeholder. Selanjutnya untuk menjawab ada tidaknya perbedaan persepsi di antara stakeholder terhadap CSR digunakan dua uji non parametrik, yaitu uji $\mathrm{H}$ Kruskal-Wallis dan uji U Mann-Whitney. Pengujian validitas dilakukan dengan product moment, sementara reliabilitas menggunakan cronbach alpha (Jogiyanto, 2004). Pengujian validitas dan reliabilitas ini dilakukan terhadap 50 responden, di luar responden yang diolah datanya.

\section{HASIL DAN PEMBAHASAN}

Mayoritas responden memiliki tingkat pendidikan S1, bahkan beberapa S2 sehingga dapat diharapkan bahwa jawaban responden berkualitas, yaitu tingkat pemahaman yang baik mengenai pertanyaan yang diajukan serta metode pengisian yang digunakan. Tabel 2 berikut menunjukkan gambaran tingkat pendidikan responden.

Tabel 2: Gambaran Responden

\begin{tabular}{lrr}
\hline $\begin{array}{c}\text { Tingkat } \\
\text { Pendidikan }\end{array}$ & Jumlah & $\begin{array}{c}\text { Persentase } \\
(\%)\end{array}$ \\
\hline SMA & 31 & 26,72 \\
D1 & 1 & 0,86 \\
S1 & 74 & 63,79 \\
S2 & 10 & 8,62 \\
Total & $\mathbf{1 1 6}$ & $\mathbf{1 0 0}$ \\
\hline Sumber: data diolah & \\
\hline
\end{tabular}

Dampak CSR terhadap Biaya dan Eksistensi

Kegiatan CSR tidak membutuhkan biaya besar dan justru memberikan dampak positif bagi eksistensi bank syariah itu sendiri. Di antara stakeholder tidak terdapat perbedaan persepsi mengenai hal ini sebagaimana hasil pengujian Kruskal-Wallis Test pada Tabel 3.

Tabel 1: Kelompok stakeholder, Metode yang digunakan dan rata-rata Reponden

\begin{tabular}{lllll}
\hline \multicolumn{1}{c}{ Target } & $\begin{array}{c}\text { Distribusi } \\
\text { Kuesioner }\end{array}$ & $\begin{array}{c}\text { Kuesioner } \\
\text { Kembali } \& \\
\text { Valid }\end{array}$ & $\begin{array}{c}\text { Rata-rata } \\
\text { Respon (\%) }\end{array}$ & \multicolumn{1}{c}{ Metodologi } \\
Nasabah & 43 & 42 & 97,67 & Dibagikan langsung \\
Karyawan & 58 & 42 & 72,41 & Dibagikan langsung \\
Masyarakat & 27 & 27 & 100 & Dibagikan langsung \\
Regulator & 10 & 5 & 50 & Email \\
Total & $\mathbf{1 3 8}$ & $\mathbf{1 1 6}$ & $\mathbf{8 4 , 0 6}$ & \\
\hline
\end{tabular}


Tabel 3: Harapan Responden terhadap

Pernyataan CSR Sebagai Biaya dan Eksistensi

\begin{tabular}{|c|c|c|c|c|}
\hline \multirow{2}{*}{ Pernyataan } & $\mathbf{N}$ & \multicolumn{3}{|c|}{ Kruskal-Willis Test } \\
\cline { 3 - 5 } & $\begin{array}{c}\text { Chi- } \\
\text { Square }\end{array}$ & Df & $\begin{array}{c}\text { Tingkat } \\
\text { Signifikansi }\end{array}$ \\
\hline $\begin{array}{l}\text { CSR membutuhkan biaya yang besar } \\
\text { dan tidak memberikan dampak positif } \\
\text { bagi eksistensi bank syariah }\end{array}$ & 116 & 3,618 & 3 & 0,306 \\
\hline
\end{tabular}

Sumber: data diolah

Hasil wawancara dengan karyawan, nasabah dan masyarakat juga menunjukkan hasil yang sama. Menurut karyawan dan nasabah CSR bagi sebuah bank syariah bukanlah merupakan biaya yang besar. Karena secara nyata memang bank syariah memiliki peran sosial, dan dana yang digunakan untuk pelaksanaan CSR pun memang sudah tersedia dari dana ZIS (zakat, infaq dan sedekah) serta qardlu hasan yang terkumpul. Jumlah yang mereka salurkan tidak dianggap sebagai biaya, tetapi manfaat. Mereka yakin apa yang mereka salurkan akan membawa berkah tersendiri. Semakin banyak manfaat yang disalurkan maka akan semakin banyak pula manfaat yang akan diterima oleh bank syariah dari waktu ke waktu. Salah satu manfaat yang diterima adalah eksistensi bank syariah yang semakin baik ditengah persaingan yang semakin ketat dalam industri perbankan.

Masyarakat awam dan bukan nasabah pun menyatakan hal yang serupa. Menurut mereka pelaksanaan CSR jangan dianggap sebagai biaya yang memberatkan. Justru sebagai hal yang menguntungkan dalam jangka panjang, misalnya eksistensi bank syariah yang semakin baik. Keuntungan jangan hanya dipandang sebagai materi, tetapi sebaiknya dipandang sebagai manfaat yang dipercaya akan membawa berkah dalam jangka panjang. Masyarakat menganggap ini merupakan tugas berat yang harus dilaksanakan oleh sebuah bank syariah. Beberapa masyarakat bahkan mengharapkan sekian persen dari profit bank syariah dipotong zakat yang nantinya digunakan untuk pelaksanaan CSR. Setelah hal ini dikonfirmasi dengan karyawan yang berhasil diwawancarai dari salah satu bank, mengatakan untuk profit cabang tidak dipotong zakat, melainkan di tingkat pusat. Kemudian akan disalurkan ke wilayah di seluruh tanah air yang membutuhkan.

\section{Dampak CSR terhadap Keunggulan Kompetitif}

Pandangan positif stakeholder terhadap CSR juga diperkuat oleh kesamaan persepsi bahwa CSR justru memberikan keunggulan kompetitif bagi bank syariah sebagaimana hasil pengujian Kruskal-Wallis Test di bawah.

Tabel 4: Harapan Responden terhadap Pernyataan CSR Bukan Keunggulan Kompetitif

\begin{tabular}{|c|c|c|c|c|}
\hline \multirow{2}{*}{ Pernyataan } & \multirow{N}{*}{\begin{tabular}{c} 
Khi- \\
\cline { 3 - 5 }
\end{tabular}} & Square & Df & $\begin{array}{c}\text { Tingkat } \\
\text { Signifikansi }\end{array}$ \\
\hline $\begin{array}{c}\text { CSR tidak memberikan keunggulan } \\
\text { yang kompetitif bagi bank syariah }\end{array}$ & 116 & 7,342 & 3 & 0,062 \\
\hline
\end{tabular}

Sumber: data diolah 
Hasil wawancara dengan karyawan, nasabah dan masyarakat menunjukkan hasil yang sama. Menurut mereka ini merupakan salah satu kelebihan yang membedakan antara bank syariah dan bank konvensional. Kelebihan ini menjadikan daya saing tersendiri bagi bank syariah. Tetapi ada seorang nasabah yang menyatakan CSR pada bank syariah bukanlah kelebihan tersendiri. Hal seperti ini adalah biasa dan memang sudah seharusnya dilaksanakan oleh sebuah bank, apalagi bank syariah. Walaupun sebagian besar menyatakan bahwa CSR merupakan keunggulan kompetitif namun pernyataan nasabah tersebut tidak bisa diabaikan begitu saja. Hal tersebut harus dijadikan cermin bahwa ada pihak yang belum merasakan CSR sebagai keunggulan yang kompetitif. Hal ini mungkin disebabkan bank syariah masih baru dan masih memfokuskan dalam menjaga kemurnian syariah dalam bertransaksi maupun dalam menciptakan produk sehingga belum maksimal menjalankan fungsi sosialnya. Hal yang serupa juga dibenarkan oleh seorang karyawan bahwa menurutnya memang belum maksimal. Artinya ini merupakan tugas besar yang harus diwujudkan oleh sebuah bank syariah agar benar-benar menjadi keunggulan yang kompetitif.

\section{Hubungan CSR dan Profit Maximization} Meskipun CSR memberikan manfaat positif bagi bank syariah, tetapi ternyata para stake holder masih berbeda pendapat bahwa CSR dan profit maximisation bagi bank syariah merupakan dua tujuan yang dapat menimbulkan konflik (Tabel 5). Hasil ini tidak mengejutkan, sebab beberapa kelompok stakeholder (masyarakat dan nasabah) masih banyak yang tidak mengetahui fungsi sosial bank syariah, atau setidaknya belum mengetahui bahwa bank syariah memiliki lembaga khusus dalam menjalankan fungsi sosialnya. Selain itu, antar nasabah dan masyarakat merasakan hal yang berbeda mengenai lembaga tersebut. Menurut mereka ada lembaga yang memang aktif menjalankan fungsinya tetapi masih ada juga yang belum optimal menjalankannya. Setelah dikonfirmasi dengan beberapa karyawan, diperoleh keterangan bahwa khusus untuk lembaga ini ada kegiatan sosial untuk cabang pengelolaannya diatur dari pusat. Artinya program apa yang hendak dijalankan harus diajukan ke pusat lebih dahulu, jika disetujui kemudian baru bisa dijalankan. Ada juga lembaga yang tidak demikian di mana cabang diberikan wewenang untuk menyalurkannya dan jika ada sisa akan disalurkan ke pusat.

Tabel 5: Harapan Responden terhadap CSR dan profit maximisation

\begin{tabular}{|c|c|c|c|c|}
\hline \multirow{2}{*}{ Pernyataan } & \multirow{2}{*}{$\mathbf{N}$} & \multicolumn{3}{|c|}{ Kruskal-Willis Test } \\
\cline { 3 - 5 } & & $\begin{array}{c}\text { Chi- } \\
\text { Square }\end{array}$ & Df & $\begin{array}{c}\text { Tingkat } \\
\text { Signifikansi }\end{array}$ \\
\hline $\begin{array}{l}\text { CSR dan profit maximization bagi } \\
\text { bank syariah merupakan dua tujuan } \\
\text { yang dapat menimbulkan konflik }\end{array}$ & 116 & 13,431 & 3 & 0,004 \\
\hline
\end{tabular}

Sumber: data diolah 
Fenomena seperti ini sebaiknya dijadikan cermin bagi bank syariah untuk dapat lebih mengoptimalkan peran sosialnya. Apalagi sambutan masyarakat tentang keberadaan bank syariah sangat baik dan banyak harapan yang mereka miliki. Seyogyanya, apapun kebijakan masingmasing bank tentang fungsi sosialnya hendaknya dilakukan koordinasi dengan baik sehingga peran social, baik yang di tingkat pusat maupun cabang sama-sama dapat berjalan dengan optimal. Akhirnya, harapan masyarakat dapat terwujud dan eksitensi bank syariah semakin baik.

\section{Dampak CSR terhadap Reputasi dan Imej}

Meskipun CSR dan profit maximization dapat bersifat conflicting, tetapi stakeholder bersepakat bahwa CSR akan merubah reputasi dan imej publik terhadap bank syariah. Tanggapan karyawan, nasabah dan masyarakat menunjukkan hasil yang sama di mana keberadaan bank syariah dengan fungsi sosial yang dimilikinya memberikan sesuatu yang berbeda kepada banyak pihak. Mereka merasa menemukan sarana yang tepat dalam bertransaksi sekaligus sebagai wadah dalam menyalurkan bantuan kepada sesama muslim. Hal ini juga menunjukkan bahwa sebagai sebuah korporasi bank syariah tidak semata-mata mengejar keuntungan semata tanpa memperhatikan kepentingan dan kesejahteraan masyarakat. Apalagi selama ini telah lama masyarakat terjebak dengan bank konvensional. Tetapi yang perlu diperhatikan sebagai evaluasi bahwa masih ada nasabah yang memiliki pandangan yang sama mengenai CSR pada bank syariah dengan bank konvensional. Artinya dalam hal lain mereka percaya bahwa bank syariah lebih baik dari bank konvensional tetapi dalam hal CSR menurutnya belum optimal pelaksanaannya. Tetapi ke depannya mereka sangat mengharapkan adanya peningkatan yang lebih baik lagi. Walaupun hanya sebagian kecil yang memiliki anggapan tersebut, tetapi hendaknya dijadikan evaluasi untuk lebih baik lagi melaksanakannya.

Tabel 6: Harapan Responden terhadap Pernyataan CSR Merubah Reputasi dan Image

\begin{tabular}{|c|c|c|c|c|}
\hline \multirow{2}{*}{ Pernyataan } & \multirow{2}{*}{$\mathbf{N}$} & \multicolumn{3}{|c|}{ Kruskal-Willis Test } \\
\cline { 3 - 5 } & & $\begin{array}{c}\text { Chi- } \\
\text { Square }\end{array}$ & Df & $\begin{array}{c}\text { Tingkat } \\
\text { Signifikansi }\end{array}$ \\
\hline $\begin{array}{l}\text { CSR akan merubah reputasi dan } \\
\text { Image publik terhadap bank syariah }\end{array}$ & 116 & 10,816 & 3 & 0,013 \\
\hline
\end{tabular}

Sumber: data diolah

\section{Level CSR Bank Syariah vs CSR Bank Konvensional}

Tabel 7: Harapan Responden terhadap Pernyataan CSR Bank Syariah vs CSR Konvensional

\begin{tabular}{|c|c|c|c|c|}
\hline \multirow{2}{*}{ Pernyataan } & \multirow{2}{*}{ N } & \multicolumn{3}{|c|}{ Kruskal-Willis Test } \\
\cline { 3 - 5 } & & $\begin{array}{c}\text { Chi- } \\
\text { Square }\end{array}$ & Df & $\begin{array}{c}\text { Tingkat } \\
\text { Signifikansi }\end{array}$ \\
\hline $\begin{array}{l}\text { Pelaksanaan CSR oleh bank syariah } \\
\text { seharusnya menunjukkan level yang } \\
\text { lebih tinggi dibandingkan bank } \\
\text { konvensional }\end{array}$ & 116 & 13,080 & 3 & 0,004 \\
\hline
\end{tabular}

Sumber: data diolah 
Bank syariah memang seharusnya menunjukkan level yang lebih tinggi dibandingkan dengan bank konvensional dalam hal pelaksanaan CSR, sebagaimana konsep teoritis bank syariah (Tabel 7).

Rata-rata responden mengakui fungsi sosial yang dimiliki bank syariah, dan karena fungsi ini maka mereka mengharapkan keaktifan dalam menjalankan fungsi tersebut. Sedangkan komitmen menurut mereka merupakan bagain akhir dari kedua hal di atas. Ketika sebuah korporasi memiliki fungsi sosial, aktif dalam menjalankan fungsi ini maka secara otomatis komitmen yang dimiliki harus lebih baik dari korporasi lainnya. Begitu juga bagi sebuah bank syariah. Ketika ratarata masyarakat mengakui fungsi social yang dimilikinya maka keaktifan dalam menjalankan fungsi ini merupakan hal yang harus dibuktikan. Untuk dapat membuktikan keaktifannya maka hal awal yang harus diperhatikan adalah komitmen. Dengan komitmen yang lebih baik terhadap fungsi ini maka setiap elemen yang terlibat didalamnya dengan sungguh-sungguh pula akan berusaha mewujudkan keaktifannya. Tetapi, yang perlu diwaspadai adalah jangan sampai program yang dilaksanakan tidak berdasarkan ketulusan hati nurani melainkan untuk tujuan popularitas semata.

\section{Bentuk CSR: Social Responsibility vs Social Activity \\ Kegiatan CSR yang dilakukan oleh} bank syariah seharusnya benar-benar menunjukkan karakternya sebagai social responsibility, bukan sekedar social activity yang bersifat karitatif dan cenderung short sight oriented.

Keterangan yang diperoleh berdasarkan hasil wawancara dengan karyawan, nasabah dan masyarakat menunjukkan bahwa menurut mereka CSR tidak hanya dilaksanakan ketika telah timbul permasalahan di masyarakat. Tanpa adanya hal tersebut pun seharusnya bank syariah aktif melibatkan diri dalam program-program kemasyarakatan. Keterangan karyawan menunjukkan bahwa selama ini mereka telah melaksanakan program-program kemasyarakatan seperti pembangunan masjid, pemberian beasiswa, perbaikan sarana pendidikan dan kesehatan, aksi donor darah, pembiayaan qadlu hasan serta banyak kegiatan kemanusiaan lainnya. Menurut mereka selama ini masyarakat menyambut baik apa yang telah dilakukan tersebut. Bahkan sebagai upaya memaksimalkan fungsi sosialnya, bank syariah bekerjasama dengan lembaga-lembaga kemasyarakatan seperti rumah zakat dan PKPU (Pos Kemanusiaan Peduli Umat).

Tabel 8: Harapan Responden terhadap

Pernyataan Corporate Responsibility vs Activity

\begin{tabular}{|ll|c|c|c|c|}
\hline \multicolumn{3}{|c|}{ Pernyataan } & \multirow{2}{*}{ N } & \multicolumn{3}{c|}{ Kruskal-Willis Test } \\
\cline { 4 - 6 } & & $\begin{array}{c}\text { Chi- } \\
\text { Square }\end{array}$ & Df & $\begin{array}{c}\text { Tingkat } \\
\text { Signifikansi }\end{array}$ \\
\hline $\begin{array}{l}\text { CSR cukup sebagai } \\
\begin{array}{l}\text { Activity corporate } \\
\text { Responsibility bukan }\end{array}\end{array}$ & Corporate & 116 & 5,474 & 3 & 0,140 \\
\hline
\end{tabular}

Sumber: data diolah 
Beberapa nasabah menilai keaktifan beberapa bank syariah dalam melakukan kegiatan kemanusiaan, meskipun beberapa dinilai belum optimal. Sebagain besar masyarakat belum bisa menilai apakah aktif atau belum, tetapi mereka memberikan saran agar kegiatan sosial yang dilakukan juga sebaiknya ditujukan untuk kegiatan yang produktif, agar setelah itu mereka dapat mandiri.

\section{Perbedaan tingkat Respon Responden}

Uji Mann-Whitney U-Test

dilakukan untuk melihat apakah perbedaan rangking juga menunjukkan perbedaaan tingkat respon dari responden. Pengujian ini diperlukan untuk mengetahui keinginan responden untuk mendukung atau tidak mendukung terhadap pelaksanaan CSR pada bank syariah, dikaitkan dengan beberapa masalah yang diajukan. Berkaitan dengan pernyataan conflicting antara CSR dan profit maximization bagi bank syariah, ternyata perbedaaan respon menunjukkan adanya perbedaan keinginan untuk mendukung atau tidak mendukung pelaksanaan CSR sesuai dengan pernyataan yang ada. Dalam hal ini berarti perbedaaan rangking menunjukkan adanya perbedaan keinginan untuk tidak mendukung pernyataan yang menyatakan CSR dan profit maximisation bagi bank syariah merupakan dua tujuan yang dapat menimbulkan konflik.

Hasil yang sama juga berkaitan dengan pernyataan tentang CSR akan merubah reputasi dan imej publik terhadap bank syariah. Perbedaan respon menunjukkan adanya perbedaan keinginan untuk mendukung atau tidak mendukung pelaksanaan CSR sesuai dengan pernyataan yang ada, bahwa CSR akan merubah reputasi dan imej publik terhadap bank syariah.

Hasil yang berbeda diperoleh berkaitan dengan pernyataan tentang pelaksanaan CSR oleh bank syariah seharusnya menunjukkan level yang lebih tinggi dibandingkan bank konvensional. Dari pengujian diketahui bahwa perbedaan respon tidak menunjukkan perbedaan keinginan untuk mendukung pernyataan yang menyatakan bahwa pelaksanaan CSR oleh bank syariah seharusnya menunjukkan level yang lebih tinggi dibandingkan bank konvensional.

Tabel 9: Hasil Uji Mann-Whitney U-Test

\begin{tabular}{|l|c|c|c|c|c|c|}
\hline \multicolumn{1}{|c|}{ Pernyataan } & $\begin{array}{c}\text { Mendukung } \\
\text { Pelaksanaan } \\
\text { CSR }\end{array}$ & $\mathbf{N}$ & $\begin{array}{c}\text { Mean } \\
\text { Rank }\end{array}$ & $\begin{array}{c}\mathbf{U} \\
\text { Value }\end{array}$ & $\begin{array}{c}\mathbf{Z} \\
\text { Value }\end{array}$ & Prob \\
\hline $\begin{array}{l}\text { CSR dan profit maximization bagi } \\
\text { bank syariah merupakan dua } \\
\text { tujuan yang dapat menimbulkan } \\
\text { konflik }\end{array}$ & Ya & 2 & $\mathrm{U}_{1}=1,50$ & & & \\
\hline
\end{tabular}

Sumber: data diolah

Tabel 10: Hasil Uji Mann-Whitney U-Test

\begin{tabular}{|c|c|c|c|c|c|c|}
\hline Pernyataan & $\begin{array}{c}\text { Mendukung } \\
\text { Pelaksanaan } \\
\text { CSR }\end{array}$ & $\mathbf{N}$ & $\begin{array}{c}\text { Mean } \\
\text { Rank }\end{array}$ & $\begin{array}{c}\mathbf{U} \\
\text { Value }\end{array}$ & $\begin{array}{c}\mathbf{Z} \\
\text { Value }\end{array}$ & Prob \\
\hline $\begin{array}{l}\text { CSR akan merubah } \\
\text { reputasi dan image publik } \\
\text { terhadap bank syariah }\end{array}$ & Ya & 114 & $\mathrm{U}_{2}=59,50$ & 0,000 & $-2,422$ & 0,015 \\
\hline
\end{tabular}

Sumber: data diolah 
Tabel 11: Hasil Uji Mann-Whitney U-Test

\begin{tabular}{|c|c|c|c|c|c|c|}
\hline \multicolumn{1}{|c|}{ Pernyataan } & $\begin{array}{c}\text { Mendukung } \\
\text { Pelaksanaan } \\
\text { CSR }\end{array}$ & $\mathbf{N}$ & $\begin{array}{c}\text { Mean } \\
\text { Rank }\end{array}$ & $\begin{array}{c}\mathbf{U} \\
\text { Value }\end{array}$ & $\begin{array}{c}\mathbf{Z} \\
\text { Value }\end{array}$ & Prob \\
\hline $\begin{array}{l}\text { Pelaksanaan CSR oleh } \\
\text { bank syariah seharusnya } \\
\text { menunjukkan level yang } \\
\text { lebih tinggi dibandingkan } \\
\text { bank konvensional }\end{array}$ & Ya & 115 & $\mathrm{U}_{2}=59,50$ & & & \\
\hline
\end{tabular}

Sumber: data diolah

\section{SIMPULAN DAN REKOMENDASI}

Dari penelitian ini nampak bahwa berbagai kelompok dalam stakeholder bank syariah menunjukkan persepsi yang sama terhadap berbagai aspek dalam CSR, yang pada intinya CSR justru akan memberikan dampak positif bagi eksistensi bank syariah itu sendiri. Hal ini menunjukkan harapan sekaligus dukungan bagi bank syariah untuk memberikan perhatian penting terhadap CSR. Harapan stakeholder ini juga tercermin dari pendapat mereka bahwa pelaksanaan CSR oleh bank syariah seharusnya menunjukkan level yang lebih tinggi dibandingkan bank konvensional. Hal ini sangat logis, sebab secara teoritis bank syariah memang didasarkan pada Islam yang memiliki komitmen tinggi terhadap sosial. Meskipun demikian, masyarakat dan nasabah menilai bahwa kegiatan CSR saat ini masih bersifat karitatif (social activity), belum menunjukkan social responsibility dalam arti sebenarnya

Hasil-hasil dalam penelitian ini merupakan bagi bank syariah, khususnya di DIY, untuk meningkatkan kegiatan CSRnya. Dan yang lebih penting, perbankan syariah hendaknya mencermati kembali apakah selama ini pelaksanaan CSR telah sesuai dengan makna CSR yang sesungguhnya. Keterbatasan dalam hal informasi yang diperoleh, lingkup penelitian, jumlah responden, kelompok stakeholder serta lingkup permasalahan hendaknya dapat dijadikan bahan pertimbangan bagi penelitian selanjutnya. sehingga hasilnya lebih bermanfaat bagi semua pihak.

\section{DAFTAR PUSTAKA}

Ahmad K., (2000), Islamic Finance and Banking: The Challenge and Prospects, Review of Islamic Economics, 9, 57-82

An-Nabhanan, M. Faruq, (2000), Sistem Ekonomi Islam Pilihan Setelah Kegagalan Sistem Kapitalis dan Sosialis, terj. Muhadi Zainuddin, Yogyakarta: UII Press

Arikunto, S., (1992), Prosedur Penelitian: Suatu Pendekatan Praktek, Cetakan ketujuh, Jakarta: Rineka Cipta

Baker Mallen, Westpac - A Case Study in Socially Responsible Banking, An Article from Business Respect, Issue Number 49, dated 9 Feb 2003, http://www.mallenbaker.net/csr/CSRfiles

Beekun, Rafik Issa, (1997), Islamic Business Ethict, Virginia: International Institute of Islamic Thought 
Cuganesan Suresh dan Khan Haider, (2006), Assessing the Reporting of Stakeholder Reciprocity in the Australian Banking Industry, Februari,

www.griffith.edu.au/school/gbs/afe/symposium/2006/proceedings/Cuganesan.pdf

Dusuki, Asyraf Wajdi, (2006), Does Corporate Social Responsibility Pay Off? An Ampirical Examination Of Stakeholder Perspective, http://mubs.mdx.ac.uk/conferences/bpcsr05/03_measuring_csr

Farook Syad dan Lanis Roman, (2005) Banking On Islam? Determinants Of Corporate Social Responsibility Disclosure, Januari 2005, http://www.afaanz.org/web2005/papers/farooksz.pdf

Friedman, M., (1996), The Social Responsibility of Business is to Increase Profits, in. M. S. Schwartz, Beyond Integrity: A Judeo-Christian Approach, Zondervan Publishing House, Grand Rapids

Gitosudarmo Indriyo, (1999), Pengantar Bisnis, Yogyakarta: BPFE

Idris, Abdul Rasyid, (2005), Corporate Social Responsibility (CSR) Sebuah gagasan dan implementasi, 22 November 2005, www.fajar.co.id/news.php

Jogiyanto, (2004), Metodologi Penelitian Bisnis, Salah Kaprah dan PengalamanPengalaman, Edisi 2004/2005, Yogyakarta : BPFE

Keraf, A. Sonny dan Imam Robert Haryono, (1995), Etika Bisnis: Membangun Etika Bisnis Sebagai Profesi Luhur, Yogyakarta: Kanisius

Karim, Adiwarman A., (2004), Bank Islam: Analisa Fiqih dan Keuangan, Edisi Ketiga, Jakarta: PT. Raja Grafindo Persada

Kartono, Kartini, (1983), Pengantar Metodologi Riset Sosial, Bandung: Alumni

Naqvi, Syeb Nawab, (1996), Etika dan Ilmu Ekonomi Suatu Sintesa Islam, Bandung: Mizan

Nika, (2005), Mendorong Implementasi Corporate Social Responsibility, 30 Mei 2005, http://www.republika.co.id/koran_detail.asp

Nurgiantoro Burhan dan Marzuki Gunawan, (2000), Statistik Terapan Penelitian Ilmu-ilmu Sosial, Cetakan I, Yogyakarta: Gajah Mada University Press

Pallant, J. (2002), SPSS Survival Manual: A Step by Step Guide To Data Analysis Using SPSS, Philadelphia: Open University Press

Parvez Zahid dan Ahmed Pervaiz,(2004), An Islamic Perspective on The Lack of Social Responsibility in Business Organisations, Working Paper Series 2004, University of Wolverhampton, UK

Phillips Robert, (2004), Some Key Questions About Stakeholder Theory, Ivey Business Journal, Maret/April, www.iveybusinessjournal.ca/view_article.asp

Singarimbun Masri dan Effendi Sofian, (1989), Metode Penelitian Survei, Edisi Revisi, Jakarta: Lembaga Penelitian, Pendidikan dan Penerangan Ekonomi dan Sosial. 
SIIERHI Vol. 10 No. 1, JANUARI 2008: $19-30$

Tanaya Jimmy, (2004), Tanggung Jawab Sosial Korporasi, The Business Watch Indonesia, dalam www. fair-biz.org.

, An Examination of Corporate Social-Environmental Disclosure in Annual Reports of Indonesian, Malaysian and Australian Islamic Banking, www.abstract.cfm.

, Corporate Responsibility Report 2005, Responsible Banking, www.barclays.com/corporateresponsibility.

, Omron Corporation Annual Report 2006, The Basic Philosophy of CSR : Working for the Benefit of Society, http://www.omron.com/ir/pdfs/ar06/ar06_19.pdf

, Corporate Social Responsibility Sebuah Gagasan dan Implementasi, 22 November 2005, www.fajar.co.id/news.php

, www.cfx.com, dalam Bias Praktek CSR di Indonesia, 11 April 2006, www. fairbiz.org

, (2006), www.biro kredit indonesia.com

, www.wikipedia.com, The Free Encyclopedia

, Annual CSR Study, MORI, 2004-05

, (2003), Global CSR Monitor

, www.syariahmandiri.com

, www.muamalatbank.com 